\title{
Maternal Obezitenin Preterm Bebeklerin Morbidite ve Mortalitesine Etkisi
}

\section{Impact of Maternal Obesity on Morbidity and Mortality of Preterm Babies}

\author{
Esra Beşer (0000-0002-3368-1514), Hayriye Gözde Kanmaz Kutman (0000-0002-3177-9411), \\ Gülsüm Kadıoğlu Şimşek (0000-0003-4831-8950), Esin Okman (0000-0002-0846-4032), \\ Burak Ceran (0000-0001-5914-5325), Fuat Emre Canpolat (0000-0001-9307-3003)
}

Ankara Şehir Hastanesi, Yenidoğan Kliniği, Ankara, Türkiye

Anahtar kelimeler

Maternal obezite, mortalite, prematürite, vücut kitle indeksi

\section{Keywords}

Body mass index, maternal obesity, mortality, prematurity

Geliş Tarihi/Received : 02.03.2021

Kabul Tarihi/Accepted : 11.03.2021

DOI:10.4274/jcp.2021.0017

Yazışma Adresi (Sorumlu Yazar)/Address for Correspondence:

Esra Beşer, Ankara Şehir Hastanesi, Yenidoğan Kliniği, Ankara, Türkiye
$\ddot{O} \mathrm{z}$

Giriş: Obezite günümüzde gelişmiş ve gelişmekte olan ülkelerin en önemli sağlık sorunları arasında yer almaktadır. Literatürde maternal obezitenin, prematüre bebekler üzerindeki etkisine ilişkin veriler sınırlıdır. Bu çalışmada maternal obezitenin preterm bebeklerin morbidite ve mortalitesi üzerine etkisinin araştırılması amaçlandı.

Gereç ve Yöntem: Gestasyon haftası $\leq 34$ olan bebeklerin dosyaları retrospektif olarak incelendi. Doğum sırasındaki maternal vücut kitle indeksine(VKİ) göre anne-bebek çiftleri iki gruba (VKI $\geq 30 \mathrm{~kg} / \mathrm{m}^{2}$ ve $\left.\mathrm{VKI}<30 \mathrm{~kg} / \mathrm{m}^{2}\right)$ ayrılarak karşılaştırıldı.

Bulgular: Toplam 100 anne-bebek çiftinin verileri analiz edildi. Doğum sırasında VKI $\geq 30 \mathrm{~kg} / \mathrm{m}^{2}$ olan $\mathrm{n}=33$ (\%33) anne saptand 1 ve Grup 1 olarak tanımland $\mathrm{VKI}<30 \mathrm{~kg} / \mathrm{m}^{2}$ olanlar Grup 2 olarak tanımlandı. Grup 1 ve 2'de ortalama gebelik yaşı sırasıyla $29,89 \pm 2,98 v e$ e $30,36 \pm 2,79(p=0,682)$ hafta ve doğum ağırlıkları $1368 \pm 512$ ve $1475 \pm 515$ ( $\mathrm{p}=0,331)$ gram idi. Grup 1'de mortalite anlamlı olarak yüksek bulundu $(\% 30,3, \mathrm{p}=0,009)$. Diğer preterm morbiditeleri her iki grupta benzer oranlardaydi. Regresyon analizinde maternal VKI $\geq 30 \mathrm{~kg} / \mathrm{m}^{2}$ olması neonatal mortalite için bağımsız risk faktörü olarak saptandı (OR 4,5, \%95CI 1,4$14,5, \mathrm{p}=0,01)$.

Sonuç: Önemli bir sağlık sorunu olan obezitenin; prematüre bebeklerde önlenebilir mortalite sebebi olması dikkat çekicidir. Yakın perinatal takibin bu sürece olumlu etkisinin olacağını düşünmekteyiz.

\footnotetext{
Abstract

Introduction: Obesity is among the most important health problems facing developed and developing countries today. Data are scarce regarding the impact of maternal obesity on preterm infants. This study aimed to investigate the effect of maternal obesity on morbidity and mortality in preterm infants.

Materials and Methods: The records of infants born at $\leq 34$ weeks of gestation were analyzed retrospectively. Mother/infant pairs were grouped according to the mother's prepartum body mass index $\left(B M I \geq 30 \mathrm{~kg} / \mathrm{m}^{2}\right.$ and $<30 \mathrm{~kg} / \mathrm{m}^{2}$ ) for comparison.

Results: Data from a total of 100 mother/infant pairs were analyzed. Prepartum BMI was $\geq 30 \mathrm{~kg} / \mathrm{m}^{2}$ in $33(33 \%)$ of the mothers and defined as group 1 . Those with a $\mathrm{BMI}<30 \mathrm{~kg} / \mathrm{m}^{2}$ were defined as Group 2. Mean gestational age in group 1 and 2 was $29.89 \pm 2.98$ and $30.36 \pm 2.79$ weeks $(p=0.682)$ and mean birth weight was $1368 \pm 512$ and $1475 \pm 515 \mathrm{~g}(\mathrm{p}=0.331)$, respectively. Mortality was found to be significantly higher in group $1(30.3 \%$; $=0.009)$. Other preterm morbidities occured at similar rates in both groups. In regression analysis, maternal $\mathrm{BMI} \geq 30 \mathrm{~kg} /$ $\mathrm{m}^{2}$ was found to be an independent risk factor for neonatal mortality (odds ratio $4.5,95 \%$ CI $1.4-14.5 ; \mathrm{p}=0.01)$.
} 
Conclusions: Obesity is a major health problem and is notable as a preventable cause of mortality in preterm infants. We believe that close perinatal follow-up may help mitigate this risk.

\section{Giriş}

Obezite günümüzde gelişmiş ve gelişmekte olan ülkelerin en önemli sağlık sorunları arasında yer almaktadır. Dünya sağlık örgütü verilerine göre obezite prevalansı 1975-2016 yılları arasında yaklaşık üç kat artmıştır (1). Genel popülasyondaki obezite artışına paralel olarak, gebelikte de obezite insidansı dünya genelinde artmaktadır. Maternal obezitenin etkilerinin, yalnızca bir nesli hedeflememesi kuşaklar aras1 obezite döngüsünün de temelini oluşturması bu konuda ki endişeleri arttırmıştır (2).

Gebelik öncesi maternal vücut kitle indeksinin $(\mathrm{VKI}) \geq 30 \mathrm{~kg} / \mathrm{m}^{2}$ olmas1 maternal, fetal ve neonatal komplikasyonlara neden olduğu bilinmektedir (3). Maternal obezojenik komorbiditelerin; perinatal mortalite, respiratuvar distres sendromu (RDS), prematüre apnesi, kronik akciğer hastalı̆̆ı, ventilatör desteği gereksinimi, konjenital defektler, uzamış hastanede kalış süresi ve mortalite için artmış bir risk taşıdı ̆̆ 1 gösterilmiştir (4-8). Ayrıca maternal obezite 28 haftadan önce doğan bebeklerde kötü nörogelişimsel sonuçlarla ilişkili bulunmuştur (9).

Obez kadınlarda gebelikte önerilen kilo artışının 5-9 kg ile sınırlı tutulmasına rağmen \%47-72'si önerilenden çok daha fazla kilo almakta ve erken doğum riski bu gebeliklerde önde gelen problemler arasında yer almaktadır (10).

Literatürde maternal obezitenin, prematüre bebeklerin morbidite ve mortalitesi ile ilişkisine ait veriler sınırlıdır. $\mathrm{Bu}$ çalışmada maternal vücut kitle indeksinin, $\leq 34$ hafta preterm bebeklerin morbidite ve mortaliteleri üzerine etkisinin araştırılması amaçlandı.

\section{Gereç ve Yöntem}

Mayıs - Kasım 2018 tarihleri arasında hastanemizde doğan, gestasyon haftas $1 \leq 34$ hafta olan ve yenidoğan yoğun bakım ünitesinde yatırılarak izlenen prematüre bebekler çalışmaya dâhil edildi. Hastaların hastane kayıt numaraları kullanılarak anne ve bebek dosyalarına ulaşıldı.

Doğum sırasındaki maternal VKI'ye göre annebebek çiftleri; VKI $\geq 30 \mathrm{~kg} / \mathrm{m}^{2}$ ve $V K \dot{I}<30 \mathrm{~kg} / \mathrm{m}^{2}$ olmak üzere iki gruba ayrıldı. Yenidoğan morbidite ve mortalitesi açısından gruplar karşılaştırıldı. Çalışma retrospektif yürütüldü. Çalışmaya başlamadan önce etik kurul onayı alındı (Etik kurul numarası 68/2019).

Vücut kitle indeksi: kilonun boya metrekare cinsinden oranı ile hesapland $1\left(\mathrm{~kg} / \mathrm{m}^{2}\right)$. Vücut kitle indeksi $\geq 30 \mathrm{~kg} / \mathrm{m}^{2}$ olan gebelerden doğan bebekler grup $1, \mathrm{VKI}<30 \mathrm{~kg} / \mathrm{m}^{2}$ olanlar grup 2'yi oluşturdu (11).

Hipotiroidi, gestasyonel diyabet, preeklampsi veya eşlik eden maternal kronik hastalık ve ilaç kullanım öyküsü gibi bilgilere hasta dosyalarından ulaşıldı. Gebelik öncesinde veya süresince tıbbi takip gerektiren herhangi bir hastalığı olmayan anneler sağlıklı gebe olarak kaydedildi.

Gebelere doğumdan en az 24 saat önce toplam 2 doz betametazon uygulanmas1; bir kür antenatal steroid uygulaması olarak tanımlandı. Bebeklerin doğumda canlandırma gereksiniminin olup olmadığ kaydedildi. Geriye dönük olarak tıbbi bilgileri ve medikal tedavileri incelendi.

Radyolojik ve klinik bulgular altında sürfaktan gereksinimi olan hastalara RDS tanıs1 konuldu. RDS yönetiminde ve sürfaktan gereksinimini değerlendirmede Türk Neonatoloji Derneği'nin önerilerine uyuldu (12). Çalışmaya dahil edilen hasta grubunda mekanik ventilasyon ihtiyacı ve süresi, izlemde tercih edilen invaziv ve non-invaziv ventilasyon ihtiyacı ve süreleri kaydedildi $(13,14)$.

Prematüre bebeklerin beslenmesinde, bakımında, izleminde karşılaşılan patent duktus arteriozus, bronkopulmoner displazi, erken ve geç neonatal sepsis, prematüre retinopatisi gibi morbiditelerin tanısi ve yönetiminde Türk Neonatoloji Derneği rehberlerinden faydalanıldı (15-20). İntraventriküler kanama Papile sinıflamasına göre derecelendirildi (21). Nekrotizan enterokolit, Bell sınıflamasına göre değerlendirildi (22).

Çoğul gebeliği olan anneler, major konjenital anomalisi olan bebekler ve dosya bilgileri eksik olan hastalar çalışma dışı bırakıldı.

\section{Istatistiksel Analiz}

İstatiksel veriler, bir kişisel bilgisayarda SPSS 22.0 yazılımı kullanılarak analiz edildi. Değişkenlerin normal dağılıma uygunluğu görsel ve analitik 
yöntemlerle incelendi. Tanımlayıcı analizler normal dağılan değişkenler için ortalama \pm standart sapma (SD), normal dağılmayan değişkenler için median (çeyrekler arası genişlik) olarak sunuldu. Bağımsız grup karşılaştırılmasında normal dağılım gösteren değişkenler, unpaired t test, normal dağılım göstermeyen değişkenler için Mann-Whitney $U$ testi kullanıldı. Kategorik değişkenler Ki-kare ya da Fisher testi kullanılarak karşılaştırıldı. Maternal VKİ ve neonatal mortalite arasındaki ilişki regresyon analizi ile araştırıldı. P değeri $<0.05$ ise anlamlı olarak kabul edildi.

\section{Bulgular}

Toplam 100 anne-bebek çiftinin verileri analiz edildi. Doğum sırasında VKI $\geq 30 \mathrm{~kg} / \mathrm{m}^{2}$ olan $n=33$ (\%33) anne saptand. Grup 1 ve Grup 2 'de bebeklerinin ortalama gebelik yaşı sırasıyla $29,89 \pm 2,98,30,36 \pm 2,79(\mathrm{p}=0,682)$ hafta ve doğum ağırlıkları 1368 $\pm 512,1475 \pm 515(\mathrm{p}=0,331)$ gram idi. Maternal yaş, doğum şekli, antenatal steroid tedavisi uygulanma, gestasyonel diyabet, preeklampsi, koryoamniyonit ve uzamış membran rüptürü oranları her iki grupta benzer bulundu (Tablo 1). Solunumla ilgili morbiditeler kıyaslandığında; sürfaktan ihtiyacı VKI $<30 \mathrm{~kg} / \mathrm{m}^{2}$ olan grupta daha fazla iken $(\% 32,8)$ bu fark istatistiksel olarak anlamlı saptanmadı $(\mathrm{p}=0,055)$. Hava kaçağı oranlarında gruplar arası fark yoktu. Hastaların invaziv ve non-invaziv mekanik ventilatör süresi, bronkopulmoner displazi oranları benzer bulundu (Tablo 2). Preterm morbiditeleri açısından incelendiğinde patent duktus arteriozus, nekrotizan enterokolit, prematüre retinopatisi, intraventriküler kanama (evre III-IV) açısından gruplar arası fark saptanmad1. (Tablo 3). Ancak mortalite oranları açısından anlamlı farklılıklar vard1: Grup 2'de mortalite oranı \%8,9 iken; Grup 1 'de mortalite oranı \%30,3 ( $\mathrm{p}=0,009)$ olarak yüksek bulundu. Regresyon analizinde maternal $\mathrm{VKI} \geq 30$ $\mathrm{kg} / \mathrm{m}^{2}$ olması neonatal mortalite için bağımsız risk faktörü olarak saptandı (OR 4,5, \%95CI 1,4-14,5, $\mathrm{p}=0,01)$.

\section{Tartışma}

$\mathrm{Bu}$ çalışma ile benzer demografik özelliklere ve postnatal morbiditelere sahip preterm bebeklerde yüksek maternal vücut kitle indeksi ile mortalite riskinin arttığı gösterilmiştir. Yaşam tarzı değişiklikleri ve beslenme alışkanlıkları nedeniyle üreme çağındaki kadınlarda artan VKİ olumsuz neonatal sonuçlara neden olduğu önceki çalışmalar ile gösterilmiştir (49). Maternal obezite nedeniyle prematüre doğum riski özellikle gestasyon haftası <33 hafta doğumlarda $\operatorname{arttığ} 1$ bilinmektedir (23). Ancak prematürelerde bu konuyla ilgili literatür verileri sınırlıdır.

Maternal obezite; perinatal-neonatal mortalite ilişkisi daha önce yayınlanmış birkaç çalışmada incelenmiştir. Tennant ve arkadaşları; erken gebelik

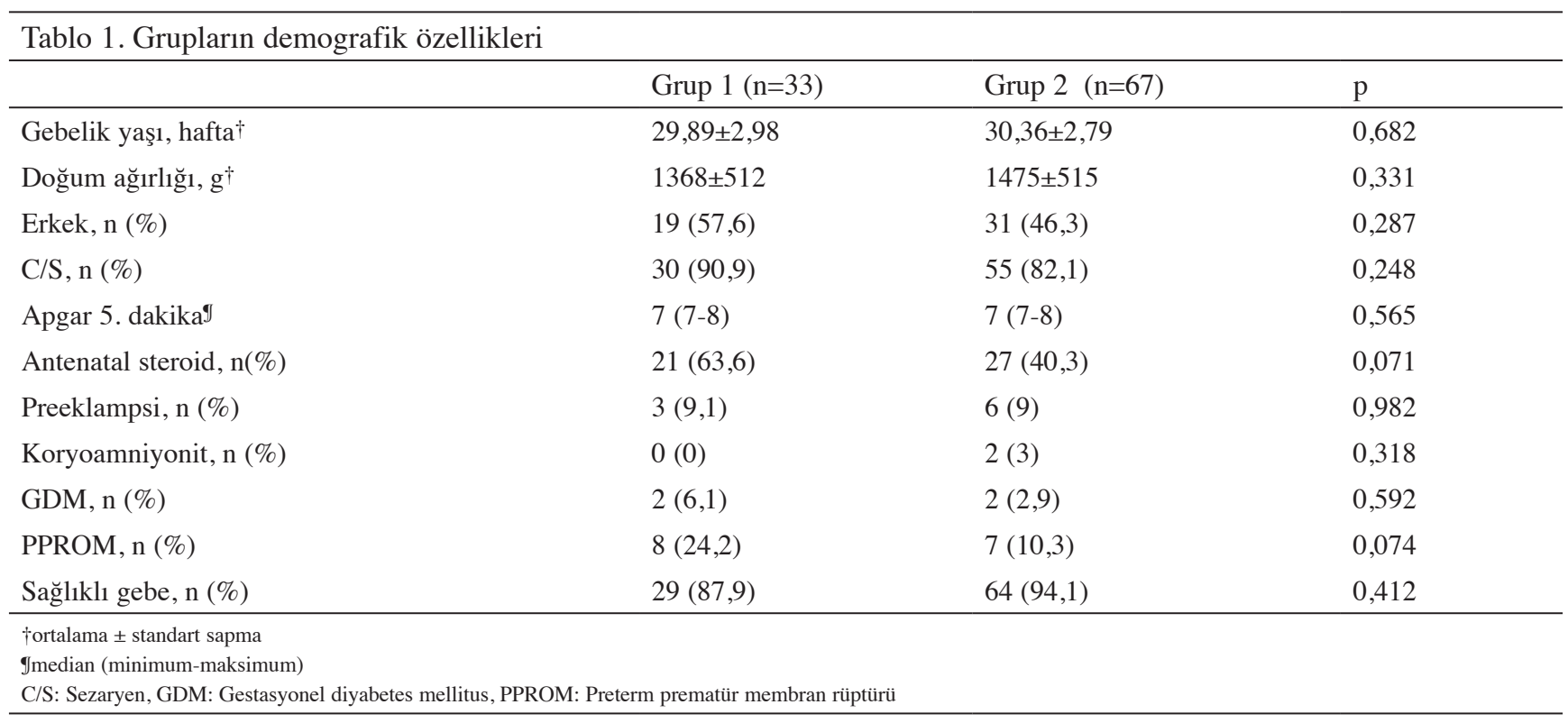


Tablo 2. Solunumla ilgili morbiditelerin karşılaştırılması

\begin{tabular}{|c|c|c|c|}
\hline & $\operatorname{Grup}_{\mathrm{n}(\%)} 1(\mathrm{n}=33)$ & $\begin{array}{l}\text { Grup } 2(\mathrm{n}=67) \\
\mathrm{n}(\%)\end{array}$ & $\mathrm{P}$ \\
\hline Sürfaktan gereksinimi, n (\%) & $8(24,2)$ & $22(32,8)$ & 0,055 \\
\hline Mekanik ventilatör süresi, gün $\dagger$ & $0(0-70)$ & $1(0-21)$ & 0,354 \\
\hline Non-invaziv mekanik ventilatör süresi, gün $\dagger$ & $2(0-88)$ & $3(0-50)$ & 0,952 \\
\hline Toplam solunum desteği süresi, gün† & $5(0-92)$ & $4(0-104)$ & 0,791 \\
\hline Pnömotoraks, n (\%) & $0(0)$ & $2(2,9)$ & 0,467 \\
\hline BPD, orta-ağır, n (\%) & $8(24,2)$ & $10(14,9)$ & 0,277 \\
\hline $\begin{array}{l}\dagger \text { †median } \\
\text { BPD: Bronkopulmoner Displazi }\end{array}$ & & & \\
\hline
\end{tabular}

Tablo 3. Preterm morbiditelerinin ve mortalitenin karşılaştırılması

\begin{tabular}{|c|c|c|c|}
\hline & $\begin{array}{l}\text { Grup } \\
n(\%)\end{array}$ & $\begin{array}{l}\text { Grup } 2(n=67) \\
\mathrm{n}(\%)\end{array}$ & $\mathrm{p}$ \\
\hline PDA, n (\%) & $7(21,2)$ & $19(28,4)$ & 0,444 \\
\hline NEK (evre $\geq \mathrm{II}), \mathrm{n}(\%)$ & $0(0)$ & $2(3)$ & 0,389 \\
\hline İntraventriküler kanama,evre III-IV, n (\%) & $3(9,1)$ & $4(6)$ & 0,819 \\
\hline ROP (lazer ihtiyacı), n (\%) & $1(3)$ & $2(3)$ & 0,573 \\
\hline Kanıtlanmış sepsis, n (\%) & $12(36,4)$ & $22(32,4)$ & 0,823 \\
\hline Hastanede yatış süresi, gün $\dagger$ & $29,32 \pm 27,88$ & $36,67 \pm 35,35$ & 0,315 \\
\hline Mortalite, $\mathrm{n}(\%)$ & $10(30,3)$ & $6(8,9)$ & 0,009 \\
\hline
\end{tabular}

döneminde obezitenin daha önce açıklanmış artmış konjenital anomali, artmış diyabet sıklı̆̆ 1 gibi mekanizmalardan bağımsız olarak fetal ve infant mortalitesini arttırdığını göstermişlerdir (24). Güncel bir meta-analizde ise maternal vücut kitle indeksindeki 1 lımlı bir artışın dahi, fetal, perinatal, neonatal veya bebek ölüm riskini arttırdığg 1 gözlenmiştir (25). Büyük çaplı bu analizde maternal VKI'deki her beş birimlik artış için; fetal ölümde 1.21 (\% 95 CI 1,09-1,35), ölü doğumda 1,24 (\% 95 CI 1,18-1,30), perinatal ölümde 1,16 (\% 95 CI 1,00-1,35), neonatal ölümde 1,15 (\% 95 CI 1,071,23 ) ve bebek ölümünde 1,18 (\% 95 CI 1,09-1,28) oranında rölatif riskin arttığı saptanmıştır (25). Bu bulgular ile benzer şekilde biz de çalışmamızda maternal $\mathrm{VKI} \geq 30 \mathrm{~kg} / \mathrm{m}^{2}$ olmasinı neonatal mortalite için bağımsız risk faktörü olarak saptadık (OR 4,5, \%95CI 1,4-14,5).

Maternal metabolik anormallikler, inflamasyon, obezite nedeniyle artan oksidatif stres ve maternal sitokin üretimi; fetal akciğer gelişimine etki ederek neonatal dönemde solunum morbiditelerine neden olabilir (26-27). Khalak ve arkadaşlarının gestasyon haftası $23^{0 / 7}$ ile $33^{6 / 7}$ olan hastalarda yapmış olduğu bir çalışmada VKI $\geq 40 \mathrm{~kg} / \mathrm{m}^{2}$ olan anne bebeklerinin; doğum salonu resusitasyon oranı ve altı saatten uzun süren ventilasyon ihtiyacı daha yüksek bulunmuştur (28). Başka bir çalışmada da maternal obezitenin solunum sikıntısı (OR 1,71,\% 95 CI 1,38-2,11) ve resusitasyon (OR 1,75,\% 95 CI 1,26$2,43)$ riskini artırdı ğ gösterilmiştir (29). Maternal vücut yağ oranı ölçümü yapılan diğer bir çalışmada ise antenatal steroid dozları tamamlanmış, gruplar arası VKİ benzer, ancak maternal yağ oran1 \%30'un üzerinde olan anne bebeklerinde RDS oranı daha yüksek saptanmıştır (30). Bu çalışmaların aksine tam kür antenatal steroid alan gebelerde VKİ'nin solunum morbiditelerini etkilemediğini gösteren çalışmalar da vardır $(31,32)$. Biz de benzer antenatal steroid oranlarına sahip çalışma grubumuzda sürfaktan ihtiyacı, RDS sıklığı ve solunum desteği süresi açısından gruplar arası fark saptamadık. 
Maternal obezite ve neonatal ölüm ilişkisini açıklamaya yönelik birçok hipotez öne sürülmüştür (25). Preeklampsi, hipertansiyon, gestasyonel diyabet gibi artmış maternal morbiditelerin fetüs/yenidoğan üzerine olumsuz etkileri olabileceği öngörülmekle beraber çalışmamızda her iki grupta perinatal riskler benzer olmasına rağmen maternal obezitenin neonatal mortalite riskini belirgin arttırdığ 1 görülmüştür.

Preeklampsi/hipertansiyon ilişkili endotel hasarı, tanımlanmamış fetal hiperglisemi, adipositokin metabolizmasındaki değişiklikler, artmış inflamasyon, enfeksiyona abartılı yanit, oksidatif hasar gibi mekanizmalar obezite ve olumsuz fetal/neonatal sonuçlar arasındaki ilişkiyi tanımlamak için öne sürülmüştür $(33,34)$. Çalışmamızda bu mekanizmaları destekleyecek maternal/neonatal bir izlem yapılmamış ya da bir belirteç çalışılmamıştır. Bu mekanizmaların kesin ve net etkilerinin anlaşılması için prospektif büyük çaplı araştırmalara ihtiyaç vardır.

\section{Çalışmanın Kısıttllıkları}

Çalışmanın en önemli kısıtlılığı retrospektif olmasıdır. Diğer bir kısıtlılık ise kısa süreli bir kohortu içermesi nedeni kısıtlı hasta sayısını içermesidir. Güçlü yanı ise benzer prenatal ve postnatal sağlık bakımı sunulmuş, morbiditeleri standart olarak yönetilmiş anne-bebek çiftlerinde maternal obezitenin neontal mortalite üzerine etkisinin gösterilmiş olmasıdır.

\section{Sonuç}

Sonuç olarak; önemli bir sağlık sorunu olan maternal obezitenin; prematüre bebeklerde önlenebilir mortalite sebebi olması dikkat çekicidir. Perikonsepsiyonel dönemde obez kadınların danışmanlık alıp ideal kiloya ulaşmaları perinatal riskleri azaltacaktır. Yakın perinatal takip gerektiren bu sürecin olası morbiditeler nedeniyle üçüncü düzey yoğun bakım ünitelerinin olduğu merkezlerde tamamlanması anne ve bebek için güvenli olacaktır.

\section{Kaynaklar}

1. World Health Organization. Obesity and overweight. 2020 (1 April 2020). Available from:URL:https://www.who.int/newsroom/fact-sheets/detail/obesity-and-overweight.

2. Mitanchez D, Jacqueminet S, Nizard J, Tanguy ML, Ciangura C, Lacorte JM, et al. Effect of maternal obesity on birthweight and neonatal fat mass: A prospective clinical trial. Plos one 2017;12(7):e0181307.

3. Marchi J, Berg M, Dencker A, Olander EK, Begley C. Risks associated with obesity in pregnancy, for the mother and baby: a systematic review of reviews. Obes Rev 2015;16(8):62138.

4. Valent AM, Hall ES, DeFranco EA. The influence of obesity on perinatal out-comes in pregnancies achieved with assisted reproductive technology: a population-based retrospective cohort study. Obstet Med 2016;9:34-9.

5. Gallardo JM, Gómez-López J, Medina-Bravo P, Juárez-Sánchez F, Contreras-Ramos A, Galicia-Esquivel M, et al. Maternal obesity increases oxidative stress in the newborn. Obesity (Silver Spring) 2015;23:1650-4.

6. Hibbard JU, Wilkins I, Sun L, Gregory K, Haberman S, Hoffman M, et al. Respiratory morbidity in late preterm births. Jama 2010;304:419-25.

7. McGillick EV, Morrison JL, McMillen IC, Orgeig S. Intrafetal glucose infusion alters glucocorticoid signaling and reduces surfactant protein mRNA expres-sion in the lung of the lategestation sheep fetus. Am J Physiol Regul Integr Comp Physiol 2014;307: R538-45.

8. Kim T, Burn SC, Bangdiwala A, Pace S, Rauk P. Neonatal Morbidity and Maternal Complication Rates in Women With a Delivery Body Mass Index of 60 or Higher. Obstet Gynecol 2017;130(5):988-93.

9. van der Burg JW, Allred EN, Kuban K, O'Shea TM, Dammann $\mathrm{O}$, Leviton A. Maternal obesity and development of the preterm newborn at 2 years. Acta Paediatr 2015;104(9):900-3.

10. Faucher MA, Hastings-Tolsma M, Song JJ, Willoughby DS, Bader SG. Gestational weight gain and preterm birth in obese women: a systematic review and meta-analysis. BJOG 2016;123:199-206.

11. Gallagher D, Heymsfield SB, Heo M, Jebb SA, Murgatroyd PR, Sakamoto Y. Healthy percentage body fat ranges: an approach for developing guidelines based on body mass index. Am J Clin Nutr 2000;72: 694-701.

12. Özkan H, Erdeve Ö, Kanmaz Kutman HG. Turkish Neonatal Society guideline on the management of respiratory distress syndrome and surfactant treatment. Turk Pediatri Ars 2018;53(Suppl 1):S45-S54.

13. Cummings JJ, Polin RA, American Academy of Pediatrics, the Committee on Fetus and Newborn. Noninvasive Respiratory Support. Pediatrics. 2016;137(1):e20153758.

14. Klingenberg C, Wheeler KI, McCallion N, Morley CJ, Davis PG. Volume-targeted versus pressure-limited ventilation in neonates. Cochrane Database of Systematic Reviews 2017, Issue 10. Art. No.:CD003666.

15. Oygür N, Önal EE, Zenciroğlu. A. Turkish Neonatal Society national guideline for the delivery room management. Turk Pediatri Ars 2018;53(Suppl 1):S3-S17.

16. Köksal N, Aygün C, Uras N. Turkish Neonatal Society guideline on the management of patent ductus arteriosus in preterm infants. Turk Pediatri Ars 2018;53(Suppl 1): S76-S87.

17. Satar M, Engin Arısoy A, Çelik İH. Turkish Neonatal Society guideline on neonatal infections - diagnosis and treatment. Turk Pediatri Ars 2018;53(Suppl 1):S88-S100.

18. Kültürsay N, Bilgen H, Türkyılmaz C. Turkish Neonatal Society guideline on enteral feeding of the preterm infant. Turk Pediatri Ars 2018;53(Suppl 1):S109-S118.

19. Arsan S, Korkmaz A, Oğuz S. Turkish Neonatal Society guideline on prevention and management of bronchopulmonary dysplasia. Turk Pediatri Ars 2018;53(Suppl 1):S138-S150. 
20. Koç E, Yağmur Baş A, Özdek Ş, Ovalı F, Başmak H. Turkish Neonatal and Turkish Ophthalmology Societies consensus guideline on the retinopathy of prematurity. Turk Pediatri Ars 2018;53(Suppl 1):S151-S160.

21. Papile LA, Burstein J, Burstein R, Koffler H. Incidence and evolution of subependymal and intraventricular hemorrhage: a study of infants with birth weights less than 1,500 gm. J Pediatr 1978;92(4):529-34.

22. Bell MJ: Neonatal necrotizing enterocolitis. N Engl J Med 1978;298:281-2.

23. Mitanchez D, Palmer PC. Review shows that maternal obesity induces serious adverse neonatal effects and is associated with childhood obesity in their offspring. Acta Paediatr 2018 Jul;107(7):1156-65.

24. Tennant PW, Rankin J, Bell R. Maternal body mass index and the risk of fetal and infant death: a cohort study from the North of England. Hum Reprod 2011;26:1501-11.

25. Aune D, Saugstad OD, Henriksen T, Tonstad S. Maternal body mass index and the risk of fetal death, stillbirth, and infant death: a systematic review and meta-analysis. Jama 2014; 311: 1536-46.

26. Villamor E, Cnattingius S. Interpregnancy weight change and risk of adverse pregnancy outcomes: a population-based study. Lancet 2006;368:1164-70.

27. McGillick EV, Lock MC, Orgeig S, Morrison JL. Maternal obesity mediated predisposition to respiratory complications at birth and in later life: understanding the implications of the obesogenic intrauterine environment. Paediatr Respir Rev 2017;21:11-18.
28. Khalak R, Rijhsinghani A, McCallum SE. Impact of maternal obesity on very preterm infants. Obesity (Silver Spring) 2017;25(5):945-9.

29. Heslehurst N, Simpson H, Ells LJ, Rankin J, Wilkinson J, Lang R, et al. The impact of maternal BMI status on pregnancy outcomes with immediate short-term obstetric resource implications: a meta-analysis. Obes Rev 2008;9:635-83.

30. Çelik HT, Korkmaz A, Özyüncü Ö, Yiğit Ş, Yurdakök M. Maternal adipose tissue, antenatal steroids, and Respiratory Distress syndrome: complex relations. Turk J Pediatr 2019;61(6):859-66.

31. Claire L, Vieux R. Efficacy of antenatal corticosteroids according to maternal and perinatal factors: a retrospective cohort study. Am J Perinatol 2015;32: 070-7.

32. Hashima JN, Lai Y, Wapner RJ, Sorokin Y, Dudley DJ, Peaceman A, et al. The effect of maternal body mass index on neonatal outcome in women receiving a single course of antenatal corticosteroids. Am J Obstet Gynecol 2010;202:263.e1-263.e5.

33. Eising JB, Uiterwaal CS, Ent CK. Maternal body mass index, neonatal lung function and respiratory symptoms in childhood. Eur Respir J 2015;46(5):1342-9.

34. Eising JB, Uiterwaal CSPM, Evelein AM, Visseren FLJ, van der Ent CK. Relationship between leptin and lung function in young healthy children. Eur Respir J 2014;43(4):1189-92. 